Ibn Al-Haitham Jour. for Pure \& Appl. Sci. 33 (4) 2020

Ibn Al Haitham Journal for Pure and Applied Science

Journal homepage: http://jih.uobaghdad.edu.iq/index.php/j/index

\title{
Synthesi and some Features of Three-Phases Polymer/Metal/Ceramic Multilayers Nanocomposite
}

\author{
Raghad S. Abbas Al-Khafaji \\ Department of Physics, College of Education for Pure Science (Ibn - Al Haitham), Baghdad, \\ Iraq. \\ raghad@,ihcoedu.uobaghdad.edu.iq \\ raghadsubhiabbas@yahoo.com
}

Article history: Received 20 January 2020, Accepted 29 January 2020, Published in October 2020.

Doi: 10.30526/33.4.2521

\section{Abstract}

Layer by layer development two features of pulsed laser deposition PLD, with a high kinetic energy and sharp instantaneous deposition rating. Layered films of polymer/metal/ceramic nanocomposites consisting of polystyrene PS(as substrate), tin Sn and cadmium oxide $\mathrm{CdO}$ were deposited by PLD. Structure for layered samples were measured by XRD X ray diffraction, there were appearance of peaks which reflected to formation of new compounds result of reaction between layers. Particles size was calculated using two methods and it give nanoscale. Microstrain was also calculated and exhibited high value (0.01) for sample $\mathrm{p} / \mathrm{m}$.

Keywords: PLD, Multilayers, XRD, microstrain, nanoscale.

\section{Introduction}

Dependent on the features of materials and budget interest, different proficiency have been occupied for the grown of thin films and the multilayers. These comprise TD thermal deposition, SD sputter deposit, CVD chemical vapor deposit, and PLD pulse laser deposit. Thermal deposit is the eldest and the utmost capable technique to growth thin films. Compared with these approaches, PLD has a singular ability to product high types of thin films of materials of several types [1]. PLD process involves concentrating an intensity laser pulse on the target surface, and transferring materials of target in the manner of some a phases of volatile (gas or plasma). Clear benefits of PLD contain its easiness of using, ever since the laser was completely de coupled from the grown chamber, and capability to reserve the stoichiometry of materials compound in optimal specifications. Latter build PLD is a 


\section{Ibn Al-Haitham Jour. for Pure \& Appl. Sci. 33 (4) 2020}

primary choice of growing complicated materials like oxides of transition metal [2-4]. In pulse laser deposit, moreover knowing by way of laser MBE when grown is measured and checked in a layer - layer way, a laser pulse with extreme and small are strikes a target and ablating the material beginning target. When the pulse of laser is absorbs in the surface level of the target, energy of electromagnetic is directly transformed into exciting the electrons in develop of Plasmon and un-bound of electrons. Electrons have been excited after then transmission their belong energy to lattice through electron - phonon $\mathrm{e}-\mathrm{p}$ pair inside a few of picoseconds. Composite nanostructured materials including of polymers and metals have a wide range of requests In thin film deposition, clusters of metal can be growth by atoms agglomeration which deposit on the substrate surface, known Vollmer Weber island growth [5-7]. Size of cluster and shape are well-defined by the growth mechanisms on the surface of substrate, which powerfully depend on the preparation conditions and on diffusion of the metal in the matrix and top its surface. The grown mechanisms conducting to the detected nanostructures have been investigated in these concerns, focusing especial on implanting effects, dissimilarities in metal diffusion and reactivity with the polymer. Further, the clusters are forming on the substrate surface because of implantation effects. Operation of the PLD comprise concentrating an intense of pulse laser top on the surface level of a target, and take out materials of target in the forming of specific volatile phases, a gas or a plasma. Separate benefits of PLD comprise its simplicity of using, pulsed laser deposition PLD is the ability to produce high energy source of particles, allowing the grown of high quality film at moderately low substrate temperature. Ultra - high instants of deposited rating and the high of energy of kinetic PLD that production the greatest critical roles. The enhanced growth, in specific for the first numerous monolayers, providing great chance to design conterfiate structures of thin films which have hopeful properties[8-10].

Synthesis of multilayers from polymer, metal and metal oxide are goal of the paper.

\section{Materials and Methods}

In this study, Polystyrene employed was provided by Polymer Chemical Company, HIMEDIA, Chloroform was used as a solvent for PS, tin Sn powder metal from ( Riedel DeHain Company ) and cadimeum oxide CdO provided from( Reagim company). Thin films of pure polystyrene PS were synthetized by applying solution - casting technique, which was used as substrate. PS was dissolved in using magnetic stirrer of hot plate at $70^{\circ} \mathrm{C}$ for $2 \mathrm{hr}$ to obtain solution with homogeneously. For extreme dispersing the solution was furthermore stirring for $2 \mathrm{hrs}$ by protection the temperature was constant. Thin films were provided by draining the solution on a washed optical plane plate of glass. The whole system was allowable to evaporat at room temperature RT in dust at liberty chamber and after that completing evaporation, the film was separate from the surface of glass. To preparation the targets, tin powder metal and cadimeum oxide ceramic powder, as individual, of 4gm weight was pressed under 4-9 ton for around $0.5-1 \mathrm{~m}$ to form the target with $1.5 \mathrm{~cm}$ diameter and 0.25 $0.3 \mathrm{~cm}$ thickness. Target must be dense as a disk to get a surface with homogenously for depositing same mass of material at all pulses process when altering the laser local beam.

Layered films of polymer/metal/ceramic nanocomposites consisting of polysrtyrene (as substrate), tin and cademium oxide were deposited by pulsed laser deposition (PLD) $\mathrm{KrF}$ excimer. Figure1. Schematic diagram of the system of the active medium is an Nd-YAG 
Ibn Al-Haitham Jour. for Pure \& Appl. Sci. 33 (4) 2020

crystal and with a fundamental wavelength of $1064 \mathrm{~nm}$, pulse duration of $10 \mathrm{~ns}$ and number of pulses 100 was use and laser energy of $200 \mathrm{~mJ}$ at room temperature of vacuum chamber made of quartz and the target is mounted inside the chamber on a stainless steel substrate with a base pressure of about 5-6 mbar chamber. Laser component was out of chamber room , and fixing for beam of laser on the surface level of the target was achieved by applying an optically lens of focally length $20 \mathrm{~cm}$. This by alternatively switching the target from $\mathrm{Sn}$ to $\mathrm{CdO}$. On the smooth polymer layers, the metal and ceramic grew in Vollmer-Weber Island growth leading for thin films of $\mathrm{Sn}$ and $\mathrm{CdO}$ to layered $\mathrm{PS} / \mathrm{Sn} / \mathrm{CdO}$. Technique of deposition (PLD) was repeated carried out with change the laying. The structure of the layered samples were studied by X-ray diffraction (XRD) (SHIMADZU JAPAN, XRD - 6000) with Cu Ka radiation $\left(\lambda=1.542 \mathrm{~A}^{\circ}\right)$ was used.

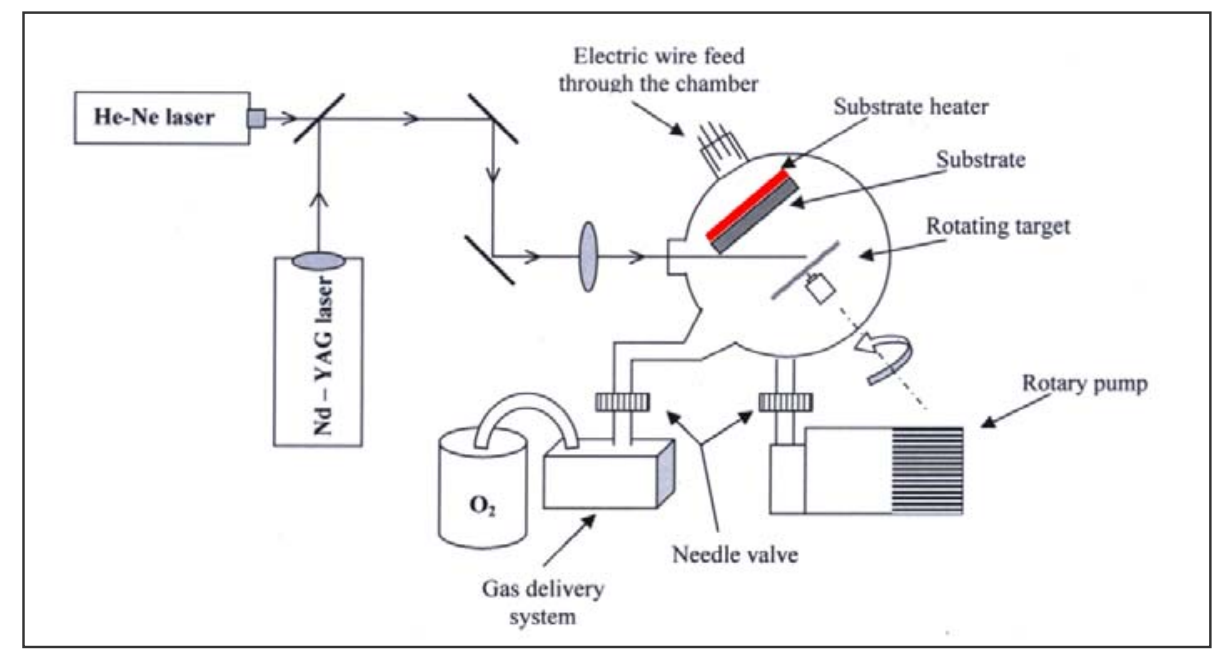

Figure 1. Schematic diagram of the system of this work.

\section{Results and Discussion}

The obtained structure was shown in the measured for X- ray diffractions and explained in Figure 2, it was note there were peaks presentation obviously, In prepared sample polystyrene pure the nature of XRD are amorphously and there was a peak at $2 \Theta=20$.

Sample of polymer/metal (p/m) with peaks at $2 \Theta=30,32,43.8$ and 64.5 for plans $(200),(101)$, (220) and (321) respectively led to tin metal layer precipitated on polymer polystyrene using pulsed laser deposition technique. Peaks for sample polymer/ceramic $(\mathrm{p} / \mathrm{c})$ at angles $2 \Theta=33$, 38, 55 and 66 reflected from plans (111), (200), (220) and (311) referred to cadmium oxide $(\mathrm{CdO})$ layer which precipitated on polymer polystyrene using same technique. New compounds appeared obviously like $\mathrm{Cd}_{2} \mathrm{SnO}_{4}$ at a round peak $2 \Theta=32.6,57$ with diffracted (311), $\mathrm{Sn}_{3} \mathrm{O}_{4}$ at peak $2 \Theta=32.8$, of plane (003), $\mathrm{SnO}_{2}$ at angle $2 \Theta=65.7,26.5$ and 37.7 reflected from plans (301), (110) and (200). 
Ibn Al-Haitham Jour. for Pure \& Appl. Sci. 33 (4) 2020
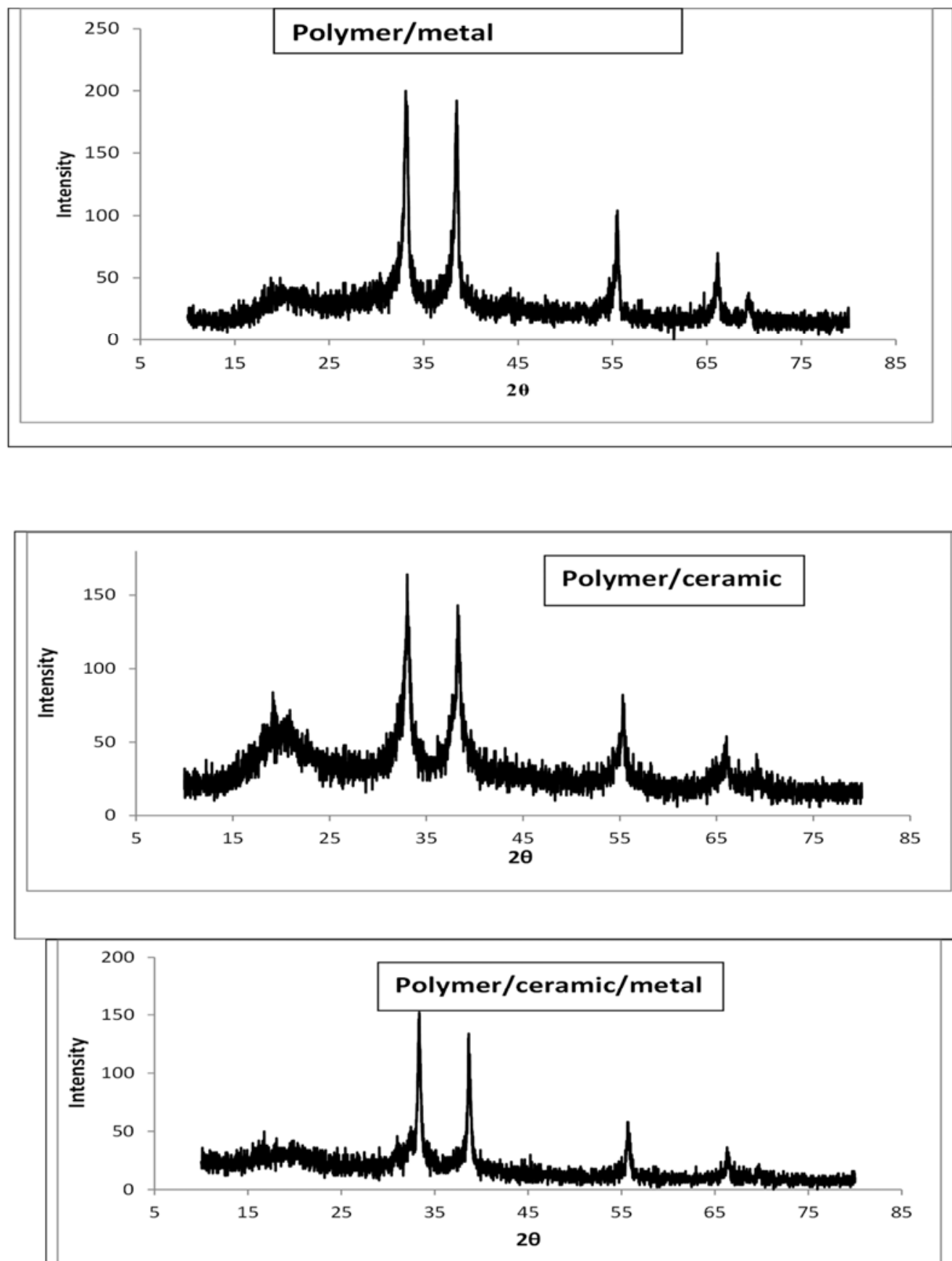
Ibn Al-Haitham Jour. for Pure \& Appl. Sci. 33 (4) 2020

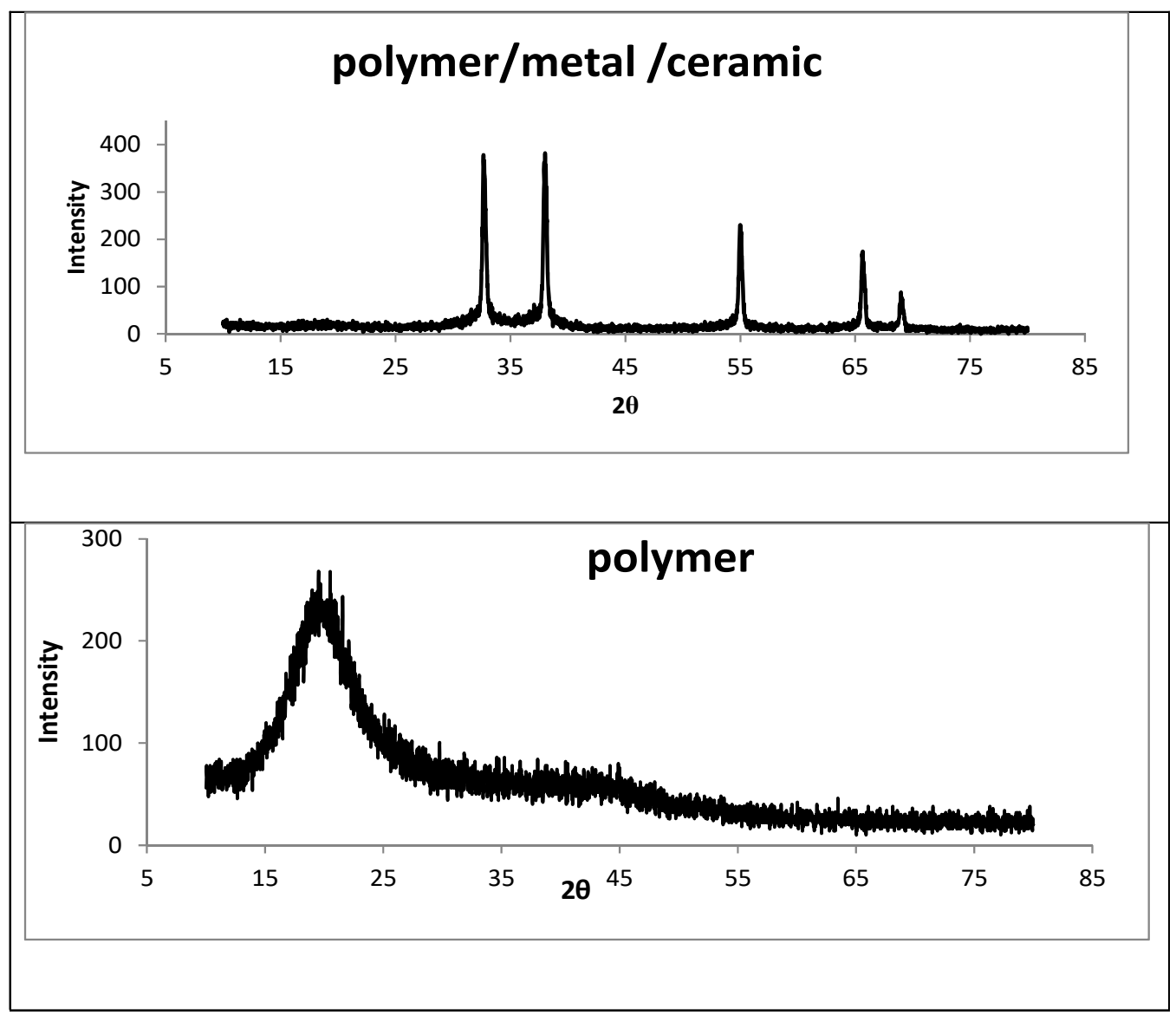

Figure 2. X- ray diffraction spectra for synthesized samples.

The average nano crystalline size was calculated using two methods. Firstly, DebyeScherrer's formula

$D=\frac{k \lambda}{\beta_{h k l} \cos \theta}$

where $\mathrm{D}=$ crystalline size, $\mathrm{K}=$ shape factor $(0.9)$, and $\lambda=$ wavelength of Cuk $\alpha$ radiation.

Secondly, Williamson-Hall (W-H) equation.

$\beta_{h k l} \cos \theta=\frac{k \lambda}{D}+4 \epsilon \sin \theta$

$\epsilon$ is microstrain, figure 3 show plot was drawn of $4 \sin \theta$ along the $\mathrm{x}$-axis and $\beta \mathrm{hkl} \cos \theta$ beside with y-axis. 
Ibn Al-Haitham Jour. for Pure \& Appl. Sci. 33 (4) 2020

Table 1. revealed all the precipitated layered samples in range of nanoparticles.

\begin{tabular}{|c|c|c|c|c|c|c|c|c|}
\hline $\begin{array}{l}\text { Sample } \\
\text { Symbol }\end{array}$ & $\begin{array}{l}\text { Layers } \\
\text { Order }\end{array}$ & $\begin{array}{l}\text { Particle } \\
\text { size(nm) } \\
\text { Method } 1\end{array}$ & $\begin{array}{l}\text { Particles } \\
\text { size(nm) }\end{array}$ & $\begin{array}{l}\text { Micro } \\
\text { strain }\end{array}$ & $\begin{array}{c}\text { Crystal } \\
\text { Structural }\end{array}$ & a $(\AA)$ & c $(\AA)$ & $\begin{array}{l}\text { Cell vol } \\
\qquad\left(\AA^{3}\right)\end{array}$ \\
\hline P1 & $\mathrm{P}$ & - & - & - & - & - & - & - \\
\hline P2 & $\mathrm{p} / \mathrm{m} / \mathrm{c}$ & 26.3913 & 17.4166 & 0.00215 & cubic & 8.07685 & - & 526.896 \\
\hline P3 & $\mathrm{p} / \mathrm{c}$ & 15.3645 & 9.1437 & 0.00475 & cubic & 4.69727 & - & 103.642 \\
\hline P4 & $\mathrm{p} / \mathrm{m}$ & 17.3625 & 20.9000 & 0.01000 & tetragonal & 4.35905 & 3.18426 & 60.510 \\
\hline P5 & $\mathrm{p} / \mathrm{c} / \mathrm{m}$ & 21.7647 & 19.7702 & 0.000675 & tetragonal & 5.66378 & 2.89525 & 92.875 \\
\hline
\end{tabular}

Aberrations from ideal crystallinity, like finite size of crystallite and strain (at the atomic scale conduct to broadening of the lines diffraction. Sources of line comprised, broadening of instrument, broadening of Crystallite Size and Strain Broadening, Elongated Defects for Stacking Faults . Anti - phase Boundaries. Elongated defects interruptted the arrangement of crystal atomic, typically along with $2 \mathrm{D}$ planes. These defects efficiently terminated a crystallographically domain ordered of the crystals. Uniform strain reasons to expand/contract unit cell in an isotropic direction[9-13]. This led to alter in a unit cell parameters and modification of the peaks. There was no broadening related to this kind of strain. Nonuniform strain guide to systematic shifts of the atoms from their ideal of positions and to peaks broaden. This kind of strain point defects (vacancies, site-disorder, etc ). In method 2 $\mathrm{W}-\mathrm{H}$ equation which included strain effect and results of the particle size for sample $\mathrm{p} / \mathrm{m}$ showing a value higher $(20.9 \mathrm{~nm})$ with micro strain $(0.01)$ than that calculated $(17.3 \mathrm{~nm})$ in method 1 of Debye-Scherrer's formula. Lattice parameters gave slightly deviation from individual metal tin and ceramic cadmium oxide, rather than, samples $\mathrm{p} / \mathrm{c} / \mathrm{m}$ and $\mathrm{p} / \mathrm{m} / \mathrm{c}$ that gave obviously deviation from pure which led to the reaction between two layers metal and ceramic 
Ibn Al-Haitham Jour. for Pure \& Appl. Sci. 33 (4) 2020
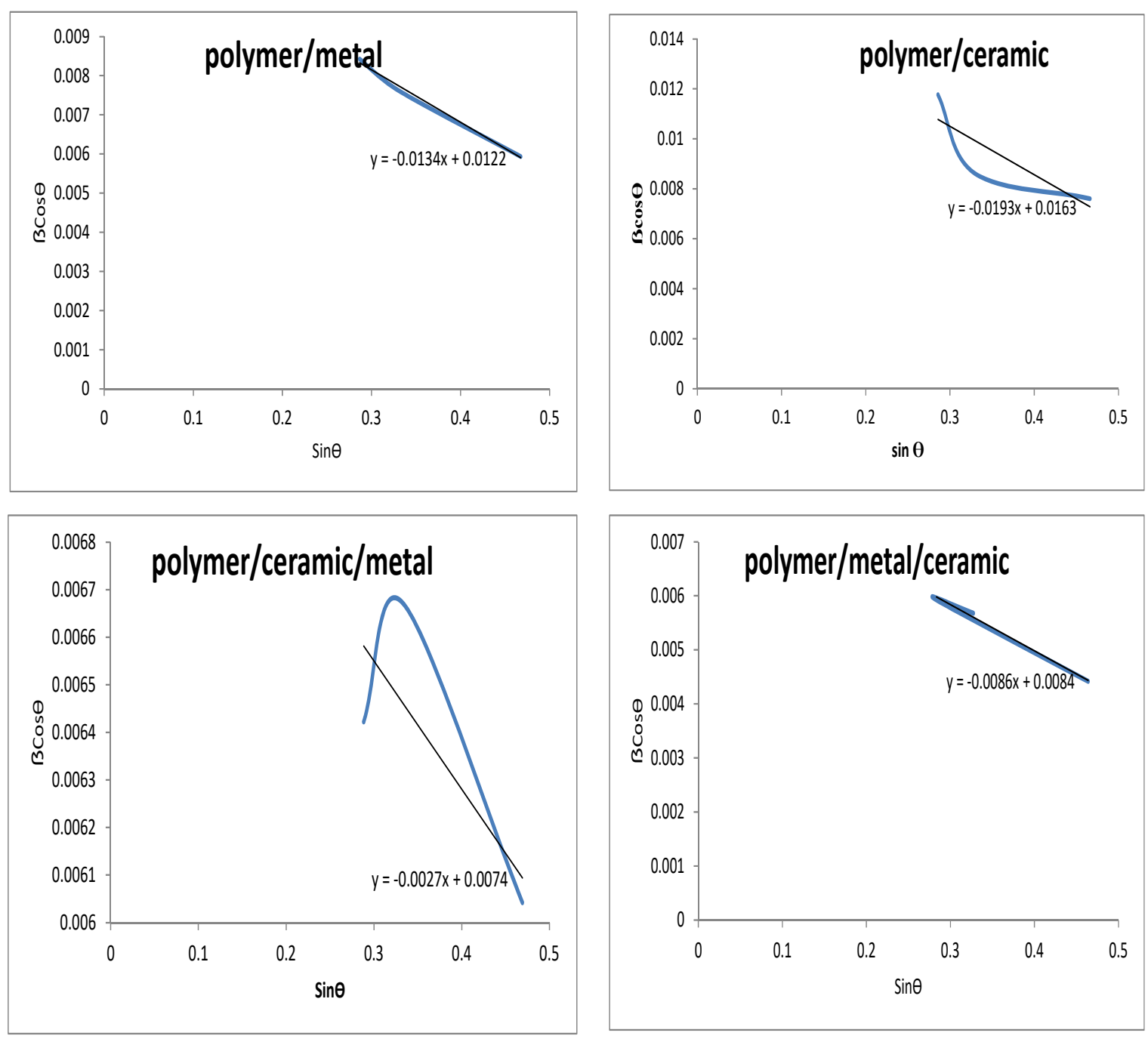

Figure 3. Plot of William - Hall equation for synthesized nanocomposites.

\section{Conclusion}

Layer by layer growing has two characteristic marks of PLD Pulse laser deposit, was a influential pr ocess to develop thin films and multilayers of difficult materials such as oxides of metal. In this state, utmost named benefits of PLD is easiness of preserving the stoichiometry the target of material. Layered films of polymer/metal/ceramic nanocomposites consisting of polysrtyrene (as substrate), tin and cademium oxide were deposited by pulsed laser deposition (PLD). Structure of layered prepared samples were studied by X-ray diffraction (XRD), there are presence of peaks which that reflected creation of new compounds result of reaction between layers. Particles size was calculated applying two methods and gave nanoscale. PLD can meaningfully improving the grown of thin films as multilayers. Micro strain also calculated and exhibited high vale for sample $\mathrm{p} / \mathrm{m}$. 


\section{Ibn Al-Haitham Jour. for Pure \& Appl. Sci. 33 (4) 2020}

\section{References}

1. George,S. ; Sebastian, M. T. Three-phase polymer-ceramic metal composite for embedded capacitor applications, Composites Science and Technology. 2009,69, 7-8, $1298-1302$.

2. AL Juhaiman,L.A.;Al-Enez,D.A. Mekhamer Reparation and Characterization of Polystyrene/Organoclay Nanocomposites from Raw Clay,

3. Digest Journal of Nanomaterials and Biostructures .2016, 11, 1, 105 - 114.

4. Nilufar K.; Nasrin S.; Mohammad H. Synthesize of dendritic fibrous nano-silica functionalized by cysteine and its application as advanced adsorbent, Nanocomposites. 2019,5,4.

5. Vijaya, S.; Sangawar; Manisha, C. Evolution of the optical properties of Polystyrene thin films filled with Zinc Oxide nanoparticles, International Journal of Scientific \& Engineering Research. 2013,4, 6.

6. Josmin, P. J.; Malhotra, S. K.; S. Thomas, K.; Joseph, K. G.; Sreekal, M. S. Advances in Polymer Composites, Polymer Composites. 2012,1,2.

7. Tjong, S. C.; Mai,Y. W. Physical properties and applications of polymer nanocomposites. 2010, Woodhead Publishing Limited, ISBN: 97-80857090249.

8. Mittal, V. Optimization of Polymer, Nanocomposites Properties. 2010,978-3-52732521-4, 440.

9. Douglas, B. C.; Graham, K. H. Pulsed Laser Deposition of Thin Films, JOHN WILEY \& SONS, INC. New York-Chichester. Brisb ane.Toronto. Singapore, 1994.

10. Gamaly, E.G; Rode A.V. ; Luther-Davies, B. Ultrafast Ablation with high-pulse-rate lasers, Journal of Appl Phys. 1999,85,8.

11. James, A.; Grant-Jacob; Jake, J., Stephen, J.; David, P. Particulate reduction in ternary-compound film growth via pulsed laser deposition from segmented binarytargets Mater. Res. Express, 2018,5, 036402.

12. Parsonage, T. L.; Beecher, S. J.; Choudhary, A.; Grant-Jacob, J. A. Pulsed laser deposited diode-pumped $74 \mathrm{~W}$ Yb:Lu2O3 planar waveguide laser, Opt. Express . 2015,23, 31691.

13. Beecher, S. J.; Grant-Jacob, J. A.;Hua, P. J.; Eason, R.W. Ytterbium-doped-garnet crystal waveguide lasers grown by pulsed laser deposition, Opt. Mater. Express. 2017, 7, 16,28-33.

14. Omer, K. Nagim T.; Abdulhadi H. Y.; Ibrahim M.A. Preparation and Characterization of A New Nano-scaled Material Composed of Bentonite-Polyethylenglycophthalate, Journal: Ibn Al Haitham Journal for Pure and Applied sciences. 2017,30,2. 